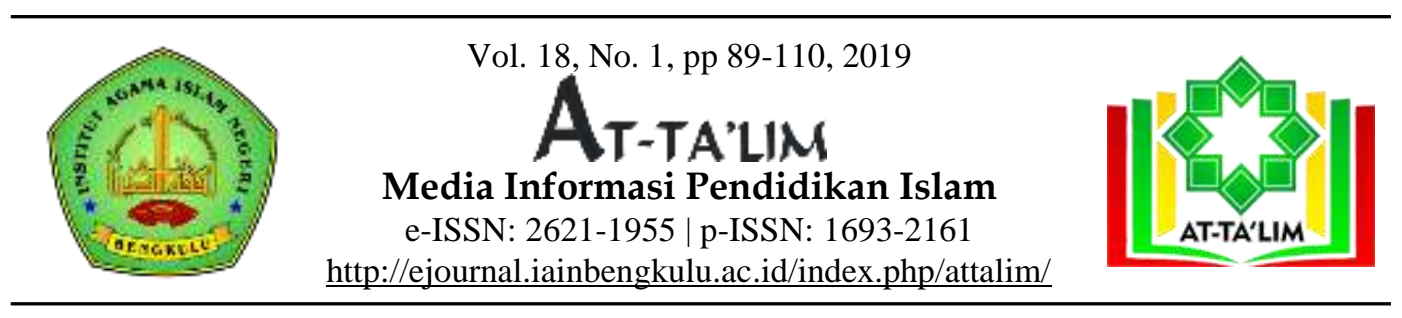

\title{
PENGEMBANGAN PEMBELAJARAN PAI BERWAWASAN ISLAM WASATIYAH : UPAYA MEMBANGUN SIKAP MODERASI BERAGAMA PESERTA DIDIK
}

\author{
KASINYO HARTO' TASTIN $^{2}$ \\ 1. masyo_71@yahoo.com \\ 2 tastin_uin@radenfatah.ac.id \\ 1,2Dosen Fakultas Ilmu Tarbiyah dan Keguruan UIN Raden Fatah Palembang \\ Sumatera Selatan, Indonesia.
}

Received : November $2^{\text {nd }} 2018$

Accepted : May 30 th 2019

Published : June 25 th 2019

\begin{abstract}
PAI Learning Development Islamic Wasatiyah Insight: Efforts to Build the Attitude of Religious Moderation of Students. The human dignity of the Indonesian people has fallen to the deepest abyss, the violence and crime that occurred is an indication that our society has shifted into a society that has lost national identity. The motive for terror is carried out over and over again about jihad fisabilillah in order to achieve a degree of martyrdom, which is a noble degree in upholding the religion of Allah. The meaning of jihad is understood literally-textualist, that is only limited to war (qital) in the physical sense by taking up arms aimed at people both individually and institutionally. Such a textual-literary understanding implies rigid, exclusive and intolerant social-religious attitudes and behaviors to people who are different from them, so that there is some kind of belief that people who are outside their group are not right (kafir) and are required fought. Our religious education seems to still be trapped in the teaching of the cognitive dogmatic realm which is teaching knowledge of rules and religious law with fiqh oriented (fiqh orientid), so the fiqh is considered as religion itself. Departing from these problems, it is necessary to reconstruct a scientific-doctrinaire-based modern learning approach. The students are allowed to inner and intellectual encroachment, so they will find maturity in religion, both in terms of their religious affections and intellectual dimensions. This research includes library research, therefore the steps to be taken are exploration of a number of data from various literatures, both primary data and secondary data. The method of data collection is done by collecting books, articles, journals, scientific opinions in which it reveals and examines the wasatiyah. The data analysis techniques using descriptive-analytic methods. The data that has been analyzed presented with the deductive method which departs from general theory to lead to conclusions to answers to the research problem. The results of the study show that applying a contextual scientific approach is a must, because the approach touches three domains: attitudes, knowledge, and skills. The result is an increase and balance between the ability to be a good human being and have the skills and knowledge to live properly. Learning about Islamic wasatiyah insight is expected to be: first, students become more aware of their own religious teachings and aware of the
\end{abstract}


reality of the teachings of other religions. Second, students are able to develop an understanding and presentation of other people's religions. Third, encourage students to participate in social activities which involve various adherents of different religions. Fourth, students can develop all of their own potential including their diversity potential, so they can control their own lives and more empowered.

Keywords: PAI Learning, Wasatiyah, Religious Moderation

Abstrak: Pengembangan Pembelajaran PAI Berwawasan Islam Wasatiyah : Upaya Membangun Sikap Moderasi Beragama Peserta Didik. Martabat kemanusiaan bangsa Indonesia sudah terpuruk ke jurang paling dalam, kekerasankekerasan dan tindak kriminal yang terjadi merupakan sebuah indikasi bahwa masyarakat kita telah bergeser normanya menjadi masyarakat yang kehilangan jatidiri kebangsaan yang ramah. Motif teror yang dilakukan lagi-lagi soal jihad fisabilillah dalam rangka mencapai derajat syahid, yang dalam agama merupakan derajat yang mulia dalam menegakkan agama Allah. Makna jihad dipahami secara literalis-tekstualis, yakni hanya sebatas perang (qital) dalam arti fisik dengan mengangkat senjata yang ditujukan kepada orang baik secara perorangan maupun kelembagaan. Pemahaman yang tekstual-literal semacam itu, berimplikasi kepada sikap dan perilaku sosial keagamaan yang rigid, eksklusif dan intoleran kepada orang yang berbeda paham dengan mereka, sehingga ada semacam keyakinan, bahwa orang yang diluar dari kelompok mereka adalah tidak benar (kafir) dan wajib untuk diperangi. Pendidikan agama kita nampaknya masih terjebak dalam pengajaran ranah kognitif dogmatis yang sibuk mengajarkan pengetahuan peraturan dan hukum agama dengan disiplin ilmu figh yang menjadi orientasinya (figh orientid) sehingga figh dianggap sebagai agama itu sendiri. Berangkat dari problematika tersebut, Maka perlu melakukan rekonstruksi pendekatan pembelajaran modern berbasis scientific-doktriner dengan demikian, peserta didik dibiarkan melakukan perambahan batin dan intelektual, sehingga kelak menemukan dalam dirinya kedewasaan dalam beragama, baik dalam hal afeksi religiusnya maupun dimensi intelektualnya. Penelitian ini termasuk library research, karena itu langkah-langkah yang akan dilakukan adalah eksplorasi terhadap sejumlah data dari berbagai literatur, baik data primer, maupun data sekunder. Metode pengumpulan data dilakukan dengan mengumpulkan buku-buku, artikel, jurnal, opini ilmiah yang didalamnya mengungkap dan mengkaji wasatiyah. Adapun teknik analisa data dengan menggunakan metode deskriptif-analytic. Data yang telah dianalisis kemudian dipaparkan dengan metode deduktif yang berangkat dari teori umum untuk menuju pada kesimpulan yang merupakan jawaban dari rumusan masalah penelitian. Hasil penelitian menunjukkan bahwa menerapkan pendekatan saintifik kontekstual merupakan suatu keharusan, karena dengan pendekatan tersebut menyentuh tiga ranah, yaitu sikap, pengetahuan, dan keterampilan. Hasilnya adalah peningkatan dan keseimbangan anatara kemampuan untuk menjadi manusia yang baik dan memiliki kecakapan dan pengetahuan untuk hidup secara layak. Pembelajaran PAI berwawasan Islam wasatiyah diharapkan dapat: pertama, peserta didik menjadi lebih sadar terhadap ajaran agama mereka sendiri dan sadar terhadap adanya realitas ajaran agama lain. Kedua, peserta didik mampu mengembangkan pemahaman dan paresiasi terhadap agama orang lain. Ketiga, mendorong peserta didik untuk berpartipasi dalam kegiatan sosaial yang di dalamnya terlibat berbagai penganut agama yang berbeda. Keempat, peserta didik dapat mengembang seluruh potensi mereka sendiri termasuk potensi keberagaman mereka 
sehingga mereka dapat mengontrol kehidupan mereka sendiri, dan dengan cara demikian mereka lebih berdaya.

Kata Kunci: Pembelajaran PAI, Wasatiyah, Moderasi Beragama

\section{To cite this article:}

Harto, K \& Tastin (2019). Pengembangan Pembelajaran PAI Berwawasan Islam Wasatiyah : Upaya Membangun Sikap Moderasi Beragama Peserta Didik. AtTa'lim: Media Informasi Pendidikan Islam, 18(1), 89-110.

\section{A. Pendahuluan}

Sikap dan prilaku bernuansa kekerasan oleh sekelompok umat Islam di Indonesia yang dilakukan atas nama agama beberapa tahun terakhir menjadi sorotan tajam masyarakat. Sorotan muncul terutama setelah munculnya pemberitaan tentang rangkaian bom bunuh diri yang waktunya tanpa berselang hari yakni minggu 13/05/18 dan senin 14/05/18. Peristiwa ini seolah menegaskan bahwa kejadian serupa bisa dan dapat terulang kapan saja seperti fenomena gunung es. Kejadian ini sedikit banyak kembali telah menciptkan citra buram wajah Islam yang selama ini dikenal dengan agama yang rahmatan lil alamin, yang mengajarkan kasih sayang dengan sesama umat manusia, apapun agama dan keyakinannya. Peristiwa ini juga menghenyak banyak komunitas negara-negara didunia terutama negara-negara yang tergabung dalam organisasi OKI karena disaat yang bersamaan kita sedang berinisiasi mengambil peran dalam menciptakan perdamaian dunia. ${ }^{1}$

Yang sulit difahami ialah motif teror yang dilakukan lagi-lagi soal jihad fisabilillah dalam rangka mencapai derajat syahid, yang dalam agama merupakan derajat yang mulia dalam menegakkan agama Allah. Terhadap pengakuan tersebut, dapat dipahami bahwa telah terjadi distorsi dan reduksi dalam menafsirkan ayat-ayat yang terkait dengan jihad yang tersurat dalam al-Qur'an dan al-Hadits. Makna jihad dipahami secara literalis-tekstualis, yakni hanya sebatas perang (qital) dalam arti fisik dengan mengangkat senjata yang ditujukan kepada orang baik secara 
perorangan maupun kelembagaan. Pemahaman yang tekstual-literal semacam itu, berimplikasi kepada sikap dan perilaku sosial keagamaan yang rigid, eksklusif dan intoleran kepada orang yang berbeda paham dengan mereka, sehingga ada semacam keyakinan, bahwa mereka, sehingga ada semacam keyakinan, bahwa orang yang diluar dari kelompok mereka adalah tidak benar (kafir) dan wajib untuk diperangi.

Kejadian ini tidak bisa hanya dilihat dari hilirnya saja tetapi juga dari hulunya, hal ini terkait dengan sikap keberagamaan dan keyakinan yang tumbuh, yang bisa saja seperti kasus bom Surabaya tersebut adalah benih-benih ekstrimisme dan radikalisme yang telah ditanam sejak 30 tahun lalu di dalam lingkungan sekolah-sekolah kita. Sejalan dengan ini sepertinya telah membawa banyak orang untuk kemudian mempersoalkan peran pendidikan, sebagai salah satu wahana pembentuk sikap keberagamaan, pendidikan sudah seharusnya menjadi basis perhatian seluruh steakholder bangsa ini, terlabih khusus pendidikan agama Islam. Sebagaimana kutipan dari seorang remaja Islam peraih nobel perdamaian Malala Yousafzai, "peluru hanya bisa menewaskan teroris, tapi hanya pendidikan-lah yang bisa melenyapkan faham terorisme sampai ke akar-akarnya (radikalisme-ekstrimisme)".

Tampaknya dalam praktek keseharian dapat disaksikan dalam keberagamaan, bahwa antara dua dimensi (amal dan iman) sering tampak tidak berimbang. Dengan kata lain, penghayatan nilai-nilai keimanan sering terpisahkan dengan peran sosial agama. Ini disebabkan disatu pihak dalam merumuskan pengertian iman dalam agama tidak mempertautkannya dengan kondisi sosial sebagai gambaran implikasinya secara praktis. Sementara dipihak lain antara nilai iman (ortodoksi) dan nilai amal (ortopraksis) dalam agama terlalu banyak mengalami kontradiksi. Akibatnya, dari ketidakseimbangan antara dua hal di atas, memunculkan kritik terhadap agama dan pemeluknya, yang dilukiskan sebagai "agama yang hanya sarat dengan doktrin-doktrin sakral, praktek 
ritual, himbauan moralitas, tidak memihak kaum lemah, tidak menyentuh persoalan-persoalan konkrit dalam masyarakat, egois, individualis, dan seterusnya. Padahal kita tahu, Islam dikenal sebagai agama rahmat untuk seluruh alam semesta (rahmatan lil alamin).

Secara normatif, pada prinsipnya tidak ada satu pun ajaran agama yang mendorong dan menganjurkan pemeluknya untuk melakukan tindak kekerasan dan kerusuhan terhadap pemeluk agama lain di luar kelompoknya. Sejumlah diskursus menunjukkan bahwa beberapa persoalan kebangsaan tersebut, lahir karena lemahnya kesadaran dan penghargaan atas perbedaan yang ada dan sikap keberagamaan yang menyimpang.

Dampak dari berbagai kasus tersebut sangat dirasakan oleh berbagai pihak, karena itu, untuk mengatasi persoalan ini, atau paling tidak untuk mengantisipasi terjadinya kasus serupa, maka diperlukan usaha yang sungguh-sungguh dan sadar dari berbagai pihak untuk mencermati, mengevaluasi dan merekonstruksi setiap upaya yang telah dilakukan di masa lalu dalam hal pola pengkajian agama Islam, baik yang berlangsung di lembaga pendidikan formal (sekolah) maupun masyarakat, mengingat selama ini Islam justru menjadi elemen keIndonesiaan, yang kuat.

Tidak dapat dipungkiri, bahwa munculnya sikap keberagamaan yang menyimpang semacam ini kemudian melahirkan sikap teror, untuk sebagaian adalah cermin ketidakberdayaan sistim pendidikan di negeri ini, khususnya pendidikan agama. Ketidakberdayaan sistim pendidikan agama di Indonseia sebagai bagian dari sistim pendidikan nasional kita secara keseluruhan, tampaknya disebabkan oleh pendidikan agama selama ini lebih menekankan pada proses transformasi ilmu agama kepada anak didik, bukan pada proses transformasi nilai-nilai luhur keagamaan kepada anak didik untuk membimbingnya agar menjadi 
manusia yang berkepribadian kuat dan beakhlak mulia sehingga tidak ada yang salah pada pola dan keyakinan keberagamaan.

Pendidikan agama nampaknya masih mementingkan huruf dari pada roh, lebih mendahulukan tafsiran harfiah di atas cinta kasih, lebih fokus pada persoalan-persoalan teoritis keagamaan yang besifat kognitif semata. Dari sini terlihat bahwa dapat dimengerti bahwa hampir semua proses pendidikan agama Islam yang berlangsung hingga sekarang, tampaknya masih terjebak dalam pengajaran ranah kognitif dogmatis yang sibuk mengajarkan pengetahuan peraturan dan hukum agama. Selain itu pembelajaran pendidikan agama Islam masih banyak memfokuskan pada isi atau muatan materi yang harus ditransfer kepada peserta didik dengan dalil-dalil dan dogma-dogma yang tidak menyentuh realitas kehidupan dan bukanya pada proses metodologi.

Hal ini mendesak untuk dilakukan karena melalui proses pendidikan terjadi sosialisasi dan internalisasi nilai dari satu generasi ke generasi berikutnya. Ketika sebuah generasi mentransmisikan nilai dengan cara yang keliru akan mempunyai dampak panjang (repurcussion) terhadap pola perilaku generasi berikutnya.

Dengan merujuk pada kasus di atas, maka salah satu solusi yang dapat ditawarkan adalah memunculkan nilai-nilai Wasatiyah (tengahan) dengan karakter utama tasamuh atau tolerasi juga nilai-nilai al-khairiyah (kebaikan), al-'adl (adil), al-yusr wa raf'ul haraj (memberikan kemudahan dan menjauhkan kesulitan), al-hikmah (bijak), al-istiqamah (keihlasan hati dalam melaksanakan kewajiban), dan al-bayniyah; bayna ifrath wa tafrith (tidak terlalu berlebihan dan tidak terlalu menyepelekan). Nilai Wasatiyah sangat kuat dasar pijaknya dalam Islam, yang salah satunya termaktub pada Q.S. AlBaqarah (2): 143, bertujuan untuk menyemai rahmat bagi sekalian alam dan sesuai Q.S. Al-Anbiya" (21): 107, sesuai konteks manusia sebagai abdullah dan khalifatullah melalui implementasi kesalehan individual dan kesalehan sosial secara seimbang. Semakin matang seseorang dalam 
beragama, maka akan semakin kompeten dalam menerapkan nilai-nilai Wasatiyah dalam kehidupan sehari-hari, terhindar dari sikap radikal yang bertentangan dengan ajaran Islam. Pengembangan metodologi pembelajaran dalam pemahaman ini dimaksudkan untuk memberikan alternatif pengembangan proses pembelajaran serta membongkar cara pandang konvensional pembelajaran kearah modern. Oleh sebab itu penelitian yang berkaitan dengan model pegembangan pembelajaran berwawasan Islam wasatiyah ini sangat penting untuk dilakukan.

Berdasarkan latar belakang masalah di atas, maka rumusan masalah penelitian ini adalah:

1. Bagaimana Problematika Pembelajaran PAI?

2. Bagaimana Model Pembelajaran PAI Perspektif Islam Wasatiyah ?

3. Bagaimana Strategi Pengembangan Sikap Moderasi Beragama Peserta didik?

\section{B. METODE PENELITIAN}

Penelitian ini termasuk library research, karena itu langkah-langkah yang akan dilakukan adalah eksplorasi terhadap sejumlah data dari berbagai literatur, baik data primer, maupun data sekunder. Metode pengumpulan data dilakukan dengan mengumpulkan buku-buku, artikel, jurnal, opini ilmiah yang didalamnya mengungkap dan mengkaji wasatiyah. Adapun teknik analisa data dengan menggunakan metode deskriptif-analytic. Data yang telah dianalisis kemudian dipaparkan dengan metode deduktif yang berangkat dari teori umum untuk menuju pada kesimpulan yang merupakan jawaban dari rumusan masalah penelitian.

\section{PEMBAHASAN}

\section{Problematika Pembelajaran PAI}

Dalam proses pembelajaran, masih terpaku pada model konvensional yang lebih menekankan penggunaan metode ceramah, 
cenderung monolog dan doktrinatif. Paradigma normatif yang selama ini lebih mendominasi dalam sistem pendidikan agama Islam, mengakibatkan muatan materi tersebut kurang membumi dan mengawang-awang sehingga kurang teraktualisasi dalam kehidupan praktis. Begitu juga pendekatan dan metode yang diterapkan dalam sistem pendidikan agama Islam mengalami kejumudan, hilangnya kreativitas berpikir di kalangan para pendidik untuk mengembangkan bermacam-macam pendekatan dan metode dalam proses pembelajarannya, karena telah dibelenggu oleh suatu idiologi yang berpandangan bahwa apa yang telah dilakukan oleh para pendahulunya itulah yang terbaik tanpa melihat konteksnya.

Ditinjau dari aspek metodologis, proses pendidikan agama Islam yang berlangsung masih lebih banyak top-down atau deduktif yang membawakan kebenaran agama dari atas sehingga kurang menghiraukan kenyataan-kenyataan yang unik yang melibatkan keseharian. Pada aspek materi tampak masih lebih dominan aspek ritualnya dengan disiplin ilmu fiqh sebagai pilihan. Pendakatan yang digunakan sangat normatif dan dogmatif, sehingga kehadiran pelajaran pendidikan agama islam terasa mebosanklan dan kurang menantang. Dengan bahasa lain pelaksanaan pendikan agama islam lebih cendrung merupakan proses teaching, proses pengajaran, ketimbang proses learning, proses pendidikan. Aspek lain dari persoalan metodologis adalah proses pendidikan agama Islam yang berlangsung adalah banking concep of education, ketimbang problem posing of education yaitu menawarkan persoalan-persialan yang problematis dan menuntut anak didik untuk berfikir kreatif dalam memecahkanya. Selama yang terjadi ialah proses pasif, dimana anak didik hanya mendengar dan menerima dari guru tanpa ada unsur kreatifitas. Kecendrungan ini berkaitan juga dengan implikasi lebih lajut dari bancing concept of education guru lebih menekankan pada 
memorasisasi, menekankan hafalan ketimbang pemikiran kritis, sehingga peserta didik yang baik menurut sistem pembelajaran seperti ini adalah anak yang penurut, tidak krtitis serta mematuhi peraturan yang ada.

Paradigma pendidikan agama Islam yang eksklusif-doktrinal yang selama ini diterapkan telah menciptakan kesadaran peserta didik untuk memandang agama lain secara berbeda, bahkan bermusuhan. Penyampaian pendidikan agama Islam kebanyakan juga terlalu menekankan doktrin "keselamatan" yang didasarkan pada kebaikan hubungan antara diri dengan Tuhan, dan kurang begitu memberikan tekanan antar sesama individu. Padahal di era multikulturalisme ini, pendidikan agama Islam mestinya melakukan reorientasi filosofis-paradigmatik tentang bagaimana memunculkan kesadaran peserta didik agar berwajah inklusif dan toleran

\section{Model Pembelajaran PAI Perspektif Islam Wasatiyah}

Dalam konteks ini pengembangan pembelajaran PAI perspektif Islam wasatiyah dalam pemahaman ini dimaksudkan untuk memberikan alternatif pengembangan proses pembelajaran serta membongkar cara pandang konvensional pembelajaran kearah modern konstruktif dengan menggabungkan pendekatan PAI yang bersifat dogmatis-normatif-doktriner, dengan pendekatan saintifikkontekstual.

Tujuan pembelajaran PAI berwawasan Islam wasatiyah diharapkan dapat: pertama, peserta didik menjadi lebih sadar terhadap ajaran agama mereka sendiri dan sadar terhadap adanya realitas ajaran agama lain. Kedua, peserta didik mampu mengembangkan pemahaman dan paresiasi terhadap agama orang lain. Ketiga, mendorong peserta didik untuk berpartipasi dalam kegiatan sosaial yang di dalamnya terlibat berbagai penganut agama yang berbeda. Keempat, peserta didik dapat mengembang seluruh potensi mereka 
sendiri termasuk potensi keberagaman mereka sehingga mereka dapat mengontrol kehidupan mereka sendiri, dan dengan cara demikian mereka lebih berdaya.

Selanjutnya pembelajaran PAI berwawasan Islam wasatiyah bisa dikembangan dengan mengacu pada beberapa prinsip pertama prinsip universal, kedua prinsip keseimbangan, ketiga prinsip integrasi, dan keempat prinsip keberagamaan. Adapun materi yang dapat dikembangkan adalah: 1) Kedamaian, 2) Penghargaan, 3) Cinta, 4) Toleransi, 5) Kejujuran, 6) Kerendahan Hati, 7) Kerjasama, 8) Kebahagiaan, 9) Tanggungjawab, 10) Kesederhanaan, 11) Kebebasan, dan 12) Persatuan.

\section{Kedamaian}

a. Memulai dengan sebuah lagu tentang kedamaian.

b. Membayangkan sebuah dunia yang damai, setelah itu refleksikan dalam bentuk tulisan kemudian tempelkan di sudut dinding sekolah.

c. Mendiskusikan Islam mengajarkan kedamaian dan bukan kekerasan.

d. Menuliskan cerita tentang kedamaian, baik berdasarkan pengalaman pribadimu atau pengalaman orang lain, kemudian dishare kepada teman-temannya di depan kelas.

e. Di akhir sesi mengajak murid-murid melakukan refleksi dengan mengatakan: damai itu indah. (The Asia Foundation, 2017: 5-14).

\section{Penghargaan}

a. Memulai dengan sebuah lagu tentang penghargaan.

b. Membayangkan sebuah dunia yang penuh dengan penghargaan. Selanjutnya menanyakan kepada para siswa apa yang akan terjadi jika setiap manusia saling menghargai satu sama lainnya. Menanyakan pula, apa yang akan terjadi jika hal-hal tersebut jarang ditunjukkan atau lakukan. 
c. Mendiskusikan tentang penghargaan memang hanya layak diberikan kepada mereka yang menang dalam melawan ketidakadilan dan segala bentuk pelanggaran.

d. Menuliskan pengalaman pribadi tentang perlakuan orang lain yang berkaitan dengan sikap menghargai atau sebaliknya, tidak menghargai terhadap apa yang telah dilakukan kepada pada siswa yang lain. (The Asia Foundation, 2017: 53-57).

\section{Cinta}

a. Memulai dengan sebuah lagu tentang kasih sayang

b. Menanyakan kepada siswa:

1) Apa makna cinta bagi Anda?

2) Pernahkah Anda dicintai?

3) Mengapa seseorang mencintai Anda?

4) Kualitas apa yang ada dalam diri Anda sehingga Anda dicintai oleh seseorang?

5) Pernahkah Anda mencintai seseorang? Mengapa Anda mencintai seseorang? Kualitas apa yang menyebabkan Anda mencintai seseorang?

6) Bagaimana jika semua orang saling mencintai?

c. Mendiskusikan tentang cinta memang terletak di hati yang terdalam, menyangkut soal emosi dan perasaan. (The Asia Foundation, 2017: 110).

\section{Toleransi}

a. Menyanyikan lagu tentang toleransi.

b. Menanyakan tentang:

1) Apa makna toleransi bagi Anda?

2) Mengapa toleransi itu penting?

3) Apa jadinya dunia ini jika tidak ada saling menghargai perbedaan?

4) Apa akibat dari konflik? 
5) Apa kerugiannya pada kemanusiaan?

c. Mendiskusikan tentang toleran adalah bagian dari iman. (The Asia Foundation, 2017: 145).

\section{Kejujuran}

a. Menyanyikan lagu tentang kejujuran

b. Membayangkan sebuah dunia yang penuh kejujuran, dituliskan dalam bentuk cerita, kemudian dishare kepada teman-temannya di depan kelas.

c. Mendiskusikan kalimat "Jujur dalam keadaan adalah keterkaitan seluruh perbuatan jiwa dan raga pada keikhlasan, serta pengerahan segala tenaga dan pencurahan seluruh kemampuan".

d. Terakhir meminta para siswa untuk melakukan sosio-drama tentang akibat dari sikap jujur dan tidak jujur. Setelah itu, siswa diminta untuk merespon tentang sosio-drama yang baru saja ditampilkan di depan kelas. (The Asia Foundation, 2017: 213216).

\section{Rendah hati}

a. Menyanyikan lagu tentang sikap rendah hati

b. Membayangkan sebuah dunia yang penuh kerendahan hati

c. Menuliskan dalam bentuk cerita, kemudian dishare kepada teman-temannya di depan kelas.

d. Mendiskusikan kalimat tentang "sikap dan sifat rendah hati akan mencegah pemutlakan paham dan pikiran serta perilaku yang angkuh. (The Asia Foundation, 2017: 213-216).

\section{Kerja sama}

a. Menyanyikan lagu tentang kerja sama

b. membayangkan sebuah dunia yang penuh dengan warna kerja sama antara satu sama lainnya 
c. Menuliskan pengalaman siswa tentang nilai kerja sama, kemudian dishare kepada teman-temannya di depan kelas.

d. Siswa dibagi menjadi 2 kelompok, kelompok pertama menggambarkan kekacauan di suatu masyarakat karena tiadanya kerja sama. Kelompok kedua menggambarkan suasana lingkungan yang harmonis karena adanya kerja sama.

e. Mendiskusikan kalimat tentang "kerja sama tidak boleh dilakukan bila dengan bingkai al-itsm dan 'udwān. (The Asia Foundation, 2017: 249-254).

\section{Kebahagiaan}

a. Menyanyikan lagu tentang kebahagiaan

b. Menanyakan tentang:

- Apa yang ingin didengar? Mengapa?

- Apa yang tidak ingin didengar? Mengapa?

- Apa yang membuatmu bahagia? Mengapa?

c. Mendiskusikan kalimat "orang-orang bahagia bisa melihat bayangan abu-abu dan mereka tahu bagaimana memprioritaskan berbagai masalah yang dihadapi serta mengubahnya menjadi sejumlah kemungkinan".

d. Melakukan refleksi dengan mengatakan:

- Kebahagiaan tidak dapat dibeli.

- Kebahagiaan tumbuh secara otomatis.

- Terima dirimu dan terima orang lain.

e. Membuat daftar yang akan membuat bahagia. (The Asia Foundation, 2017: 294-300).

\section{Tanggung jawab}

a. Menyanyikan lagu tentang tanggung jawab

b. Membayangkan apa yang terjadi jika semua manusia di muka bumi ini melakukan segala sesuatu dengan penuh tanggung jawab 
c. Menuliskan dalam bentuk cerita kemudian dishare kepada teman-temannya di depan kelas

d. Mendiskusikan kalimat tentang "siapa yang tidak amānah, maka ia tidaklah beriman". (The Asia Foundation, 2017: 333-335).

10. Kesederhanaan

a. Menyanyikan lagu tentang kesederhanaan

b. Menanyakan:

- Apa makna kesederhanaan bagi Anda?

- Ambillah beberapa contoh dari Rasulullah saw atau dari para sahabat beliau tentang kesederhanaan, kemudian share dengan teman-temannya

c. Mendiskusikan kalimat tentang "orang yang menghidupkan nilai kesederhanaan adalah mereka yang moderat dalam perilaku dan memperlakukan orang lain". (The Asia Foundation, 2017: 371-378).

\section{Kebebasan}

a. Menyanyikan lagu tentang kebebasan

b. Siswa diajak untuk mengamati masalah-masalah yang terjadi di sekitar lingkungannya. Mereka pasti punya masalah yang ingin disampaikan. Misalnya, pemaksaan, tertekan oleh lingkungan, terbelenggu, dan sebagainya. Meminta mereka untuk menuliskannya di papan tulis. Setelah daftar masalah tersusun, mereka menilai sendiri dalam bentuk tertulis, atau dalam diskusi kelompok tentang faktor apa yang menyebabkan masalah tersebut, dan nilai apa yang membantu untuk memecahkan masalah.

c. Mendiskusikan kalimat tentang "seseorang disebut bebas atau memiliki kebebasan bila ia dapat melakukan sesuatu seperti dikehendakinya sendiri atas pilihan serta pertimbangannya sendiri dan tindakannya itu merupakan kelanjutan dan 
konsistensi dari kepribadiannya" . (The Asia Foundation, 2017: 411-417).

\section{Persatuan}

a. Menyanyikan lagu tentang persatuan

b. Membayangkan apa yang terjadi jika dulu manusia Indonesia tidak bersatu melawan penjajah

c. Menuliskan dalam bentuk cerita, kemudian share kepada teman-temanmu di depan kelas.

d. Mendiskusikan kalimat tentang "persatuan adalah perasaan dan sikap menjadi bagian tak terpisahkan dari yang lain. (The Asia Foundation, 2017: 445-448).

Adapun untuk kompetensi Guru PAI harus memiliki pengetahuan agama yang luas dan dapat mengajarkan pengetahuan agama tersebut secara dinamis. Selain itu guru PAI harus mengatur dan mengorganisir isi, proses, situasi dan kegiatan PAI secara wasatiyah, dimana setiap siswa dari berbagai suku, gender, ras, kesempatan untuk mengembangkan dirinya dan saling menghargai perbedaan.

\section{Strategi Pengembangan Sikap Moderasi Beragama Peserta didik}

Profile karakter muslim moderat yaitu berperilaku normal (tawassut) di dalam mengimplementasikan ajaran agama, toleran terhadap perbedaan pendapat, menghindari kekerasan, memprioritaskan dialog, mengakomodir konsep-konsep modern yang secara substansial mengandung maslahat, berpikir rasional berdasarkan wahyu, menafsirkan teks secara kontekstual, dan menggunakan ijtihad di dalam menafsirkan apa yang tidak termaktub di dalam al-Qur'an atau Sunnah. Dengan karakter ini, Islam moderat adalah mereka yang memiliki sikap toleran, rukun dan kooperatif dengan kelompok-kelompok agama yang berbeda. Inilah watak rahmah bagi Islam moderat Indonesia. 
Wasathiyah (sikap moderat) dalam Islam, tidak hanya terbatas pada suatu aspek kehidupan tertentu saja, melainkan mencakup seluruh aspek kehidupan. Adapun aspek-aspek sikap moderat yaitu: Pertama, moderat dalam pembelajaran dengan menerapkan saintifikdoktriner yang perlu dilakukan: 1) Materi pembelajarannya berbasis pada fakta atau fenomena yang dapat dijelaskan dengan penalaran tertentu. 2) Mendorong dan menginspirasi siswa berpikir secara kritis, analistis, dan tepat dalam mengidentifikasi, memahami, memecahkan masalah, dan mengaplikasikan materi pembelajaran PAI. 3) Mendorong dan menginspirasi siswa mampu berpikir hipotetik dalam melihat perbedaan dan kesamaan. 4) Mendorong dan menginspirasi siswa mampu memahami, menerapkan, dan mengembangkan pola berpikir yang rasional dan objektif. 5) Berbasis pada konsep, teori, dan fakta empiris yang dapat dipertanggungjawabkan. 6) Tujuan pembelajarannya dirumuskan secara sederhana dan jelas.

Kedua, Moderat dalam pemikiran dan perilaku. Hal ini tercermin dalam konsep ukhuwah Islamiyah, seseorang merasa saling bersaudara satu sama lain karena sama-sama memeluk agama Islam. Umat Islam yang dimaksudkan bisa berada di belahan dunia mana pun. Dalam konsep ukhuwah wathaniyah, seseorang merasa saling bersaudara satu sama lain karena merupakan bagian dari bangsa yang satu, misalnya bangsa Indonesia. Ukhuwah model ini tidak dibatasi oleh sekat-sekat primordial seperti agama, suku, jenis kelamin, dan sebagainya. Adapun, dalam konsep ukhuwah basyariyah, seseorang merasa saling bersaudara satu sama lain karena merupakan bagian dari umat manusia yang satu yang menyebar di berbagai penjuru dunia. Dalam konteks ini, semua umat manusia sama-sama merupakan makhluk ciptaan Tuhan. Adapun sikap yang dikembangkan dengan cara: 1) Menjalankan salat berjamaah, 2) Membantu orang lain, 3) memaafkan kesalahan orang lain 4) bertegur 
sapa 5) melupakan perbedaan merajut kebersamaan 6) Memperkuat dan meningkatkan silaturahim, 7) mejauhi perbuatan maksiat 8) medoakan orang lain 9) berlomba-lomba dalam kebaikan 10) ikhlas menerima kritikan 11) tidak merasa diri selalu benar.

Ketiga, Moderat dalam metode. Hal ini tercermin dalam: 1) sudut pandang yang universal. Islam ikut andil dan berkontribusi melalui risalah agama untuk memperbaiki kehidupan masyarakat tatanan politik negara, pembentukan umat, kebangkitan bangsa, dan reformasi kehidupan. Islam adalah agama yang sangat sempurna, karena Islam adalah akidah dan syariat; dakwah dan negara; perdamaian dan jihad; kebenaran dan kekuatan; ibadah dan muamalah. 2) Perioritas dalam pemahaman. Sudut pandang yang moderat, menuntut kita untuk mendahulukan perkara yang wajib atas perkara yang sunnah; perkara yang bermanfaat luas atas perkara yang manfaatnya terbatas; dan perkara yang universal atas perkara yang parsial. Mengetahui perkara yang utama, melaksanakannya dan mendahulukannya atas perkara yang memiliki tingkat urgensi lebih rendah, termasuk perkara yang sangat penting.

\section{KESIMPULAN}

Hasil penelitian menunjukkan bahwa menerapkan pendekatan saintifik kontekstual merupakan suatu keharusan, karena dengan pendekatan tersebut menyentuh tiga ranah, yaitu sikap, pengetahuan, dan keterampilan. Hasilnya adalah peningkatan dan keseimbangan anatara kemampuan untuk menjadi manusia yang baik dan memiliki kecakapan dan pengetahuan untuk hidup secara layak. Pembelajaran PAI berwawasan Islam wasatiyah diharapkan dapat: pertama, peserta didik menjadi lebih sadar terhadap ajaran agama mereka sendiri dan sadar terhadap adanya realitas ajaran agama lain. Kedua, peserta didik mampu 
mengembangkan pemahaman dan paresiasi terhadap agama orang lain. Ketiga, mendorong peserta didik untuk berpartipasi dalam kegiatan sosaial yang di dalamnya terlibat berbagai penganut agama yang berbeda. Keempat, peserta didik dapat mengembang seluruh potensi mereka sendiri termasuk potensi keberagaman mereka sehingga mereka dapat mengontrol kehidupan mereka sendiri, dan dengan cara demikian mereka lebih berdaya.

\section{E. DAFTAR PUSTAKA}

Abd al-Baqi, Fuad Muhammad (1992). Al-Mu'jam al-Mufahras li Alfaz alQur'an al-Karim. Beirut: Dar al-Fikr.

Abou El-Fadl, Khaled M (2006). Selamatkan Islam dari Muslim Puritan, terj. Helmi Mustofa. Jakarta: Serambi Ilmu Semesta.

Abdullah, Amin (2008). “Desain Pengembangan Akademik IAIN menuju UIN Sunan Kalijaga: dari penekatan Dikotomis-Atomistis ke arah integratif-interdisiplinary" dalam Zainal Abidin Bagir, Integrasi Ilmu dan Agama, Yogyakarta: Pustaka Pelajar.

Agustriana, N. (2019). PENGARUH METODE EDUTAINMENT DAN IDENTITAS DIRI TERHADAP KETERAMPILAN SOSIAL ANAK. Al-Fitrah, 1(2), 216-228. Retrieved from http:/ / ejournal.iainbengkulu.ac.id/index.php/alfitrah/article/vie $\mathrm{w} / 1517$

Ali, Muhammad, (2007). "Moderate Islam Movement in Contemporary Indonesia," in Islamic Thoughts and Movements in Contemporary Indonesia, ed. oleh Rijal Sukma dan Clara Joewono Jakarta: Center for Strategic and International Studies.

Amal, Adnan Taufik, (1994). Islam dan Tantangan Modernitas (Studi atas Pemikiran Hukum Fazlur Rahman). Bandung: Mizan.

Al Asfahani Ragib. Mufradat Alfaz al Qur'an. Damaskus: Dar al Qalam, jilid. II

Al Barry dan Partonto, (2001). Kamus Ilmiah Populer. Surabaya, Arkola. 
Purwadarminto, W.J.S., (1976). Kamus Umum Bahasa Indonesia. Jakarta: Balai Pustaka.

Al-Maragi, Mustafa Ahmad. Tafsir al-Maraghi Jilid V, (t.t.: Dar al-Fikr, $1974 / 1394$

Al Qaradawi, Yusuf, (1983). al Khasa'is al 'Ammah li al Islam. Bairut: $\mathrm{Mu}^{\prime}$ assasah al-Risalah.

Al Tabari, Ibnu Jarii, (1389). Jami' al-Bayan 'an Ta'wibal-Qur'an Tafsir alTabari, Jilid, II.

Azra, Azyumardi, (2003). "Bali and Southeast Asian Islam: Debunking the Myths," in After Bali: The Threat of Terrorism in Southeast Asia, ed. oleh Kumar Ramakrishna dan See Seng Tan (Singapore: World Scientific Publishing Co. Pte. Ltd.

Badruzaman, Ahmad (2006). Strategi dan Pendekatan dalam Pembelajaran. Yogyakarta, ar-Ruzz.

Burhani, Najib Ahmad. "Al-Tawassut wa-l I'tidāl: The NU and Moderatism in Indonesian Islam," Asian Journal of Social Science 40, no. 5-6 (2012): 564-581.

Burhani, Najib Ahmad (2007). "Pluralism, Liberalism and Islamism: Religious Outlook of the Muhammadiyah Islamic Movement in Indonesia" Tesis, Faculty of Humanities, University of Manchester.

Daradjat, Zakiah (1996). Ilmu Pendidikan Islam. Jakarta,Bumi Aksara.

Depdiknas. (2002). Pendekatan Kontekstual dalam Pembelajaran. Jakarta: Depdiknas.

Dimyati dan Mudjiono (1994). Belajar dan Mengajar. Jakarta; Rineka Cipta

Esposito, L. John and Voll O. John. (2001). Tokoh-tokoh Gerakan Islam Kontemporer. Jakarta: PT RajaGrafindo Persada

Harto, Kasinyo, (2004). Model Pengembangan Pendidikan Agama Islam Berbasis Multikultural. Palembang: Excellent. 
Rekonstruksi Metodologi Pendidikan Agama Islam ; Upaya Membangun Karakter Keberagamaan Peserta Didik Yang Wasathiyah., Orasi Ilmiah Dalam Rangka Pengukuhan Guru Besar Dalam Bidang Metodologi Pendidikan FITK UIN Raden Fatah Palembang. 10 Mei 2017.

Hanafi, M. Muchlis (2013). Moderasi Islam: Menangkal Radikalisasi Berbasis Agama. Jakarta: Ikatan Alumni al-Azhar dan Pusat Studi al-Qur'an.

Hamalik, Oemar (2004). Proses Belajar Mengajar. Jakarta: Bumi Aksara

Hilmy, Masdar "Whither Indonesia's Islamic Moderatism? A Reexamination on the Moderate Vision of Muhammadiyah and NU," Journal of Indonesian Islam 7, no. 1 Juni 2013: 25.

Jokowi, "Indonesia Sumber Pemikiran Islam Dunia," diakses 9 September 2016, https://www.kemenag.go.id/berita/387579/presidenjokowi-indonesia-sumber-pemikiran-islam-dunia.

Kamus Besar Bahasa Indonesia. (2005). Jakarta: Balai Pustaka, Edisi Ketiga.

Kementrian Agama RI, (2010). Syaamil al-Qur'an: Miracle The Reference, 22 Keunggulan Yang Memudahkan dalam 1 al-Qur'an Dengan Referensi yang Sahih, Lengkap, dan Komprehensif. Bandung: Sygma Publishing.

Kuntowijoyo, (2004). Islam sebagai Ilmu: Epistemologi, Metodologi dan Etika. Yogyakarta: Teraju

Kusumah, R. G. T. (2019). Peningkatan Kemampuan Berfikir Kritis Mahasiswa Tadris IPA Melalui Pendekatan Saintifik Pada Mata kuliah IPA Terpadu. IJIS Edu: Indonesian Journal of Integrated Science Education, 1(1), 71-84. Retrieved from http:// ejournal.iainbengkulu.ac.id/index.php/ijisedu/article/vie $\mathrm{w} / 1762$

Kusumah, R. G. T., \& Munandar, A. (2017). Analysis Of The Relationship Between Self Efficacy And Healthy Living Conciousness Toward Science Learning Outcome. EDUSAINS, 9(2), 132-138. https://doi.org/10.15408/ES.V9I2.2183

Madjid, Nurcholis (2008). Islam Doktrin dan Peradaban, cet. Ke-6 Jakarta: Paramadina Bekerjasama dengan Dian Rakyat. 
Madjid, Abdul dan Andayani, Dian (2005). Pendidikan Agama Islam Berbasis Kompetensi. Bandung: PT. Remaja Rosda Karya.

Mashadi, Imron (2009). Pendidikan Agama Islam dalam Perspektif Multikulturalisme, "Reformasi PAI di Era Multikultural". Jakarta: Balai Litbang Agama.

Mujiburrahman, (2008). Mengindonesiakan Islam: Representasi dan Ideologi, I. Yogyakarta: Pustaka Pelajar.

Mulyasa, E (2006). Kurikulum Tingkat Satuan Pendidikan. Bandung: Remaja Rosdakarya.

Muhith, Faizin Nur. Menguak Rahasia Cinta Dalam Al-Qur'an. Surakarta: Indiving Publishing.

Nata, Abuddin (2016). Ilmu Pendidikan Islam. Jakarta: Kencana.

Nashir, Haedar. Gerakan Islam Syari'at (Reproduksi Salafiyah di Indonesia). Qardhawi, Yusuf 1993. Islam Ekstrem (Analisis dan Pemecahannya). Bandung: Mizan.

Nasution, Harun (1995). Islam Rasionalis (Gagasan dan Pemikiran). Bandung: Mizan.

Nurdin, Ali (2006). Qur'anic Society; Menelusuri Konsep Masyarakat Ideal dalam Al-Qur'an. Jakarta: Erlangga.

Nuh, bin Abdullah, (1993). Kamus Baru Jakarta: Pustaka Islam.

Pidato SBY di depan peserta APEC CEO Summit 2011 di Honolulu Maktab I'lamiy Hizbut Tahrir Indonesia NO: 214/11/11 18 November 2011/22 Dzulhijjah 1432 H

Qardhawi, Yusuf. (1994). Memahami Karakteristik Islam: Kajian Analitik, Surabaya: Risalah Gusti.

Qasim, Syarif Aun, (1980). Fi al-Tariq ila al-Islam. Beirut: Dar al-Qalam

Qutb, Sayyid, Fi Zilal al-Qur'an, Jilid V, Bairut: Dar al-Ihya al-Turas \al'Arabi. 
Sabiq, Sayyid, (2000). al-Figh al-Sunnah. Jilid II, Qahirah:, Dar al-Fath Lil I'lam al-'Arabiy.

Sagala, Syaiful (2003). Konsep dan Makna Pembelajaran. Bandung : Alfabeta.

Salim, Abd. Muin, (1994). Fiqhi Siyasah Konsep Kekuasaan Politik Dalam AlQur'an. Jakarta: Lembaga Studi Islam dan Kemasyarakatan.

Suprayogo, Imam Paradigma Pengembangan Keilmuan pada Perguruan Tinggi: Konsep Pendidikan Tinggi yang Dikembangkan UIN Malang. Malang: UIN Malang Press.

Shihab, Quraish, (2006). Wawasan Al-Quran Tafsir Maudhu'i atas Pelbagai Persoalan Umat.

Sirry A. Mu'nim, (2003). Membendung Militansi Agama (Iman dan Politik dalam Masyarakat Modern). Jakarta: Erlangga.

Syu'aibi, Ali (2010). Meluruskan Radikalisme Islam Terj. Muhtarom tp: Duta Aksara Mulia.

Taher, S. Lukman. Damai untuk Kemanusiaan, Strategi dan Model Komunikasi Antara Umat Beragama di Sulawesi Tengah. Palu: USAID-FKUB Sulteng.

Tillman, Diane. (2010). Living Values Activities for young adults Pendidikan Nilai Untuk Kaum Dewasa Muda. Jakarta: PT Gramedia Widiasarana Indonesia.

\footnotetext{
${ }^{1}$ Kompas, "Inilahlm Deretan Aksi Bom Bunuhlm Diri di Indonesia HLMalaman all," KOMPAS.com,May14,2018,hlmttps://nasional.kompas.com/read/2018/05/14/13533731/inilahlmd eretan-aksi-bom-bunuhlm-diri-di-indonesia.
} 